\title{
The role of ice thickness and bed properties on the dynamics of the enhanced-flow tributaries of Bailey Ice Stream and Slessor Glacier, East Antarctica
}

\author{
David M. RIPPIN, ${ }^{1}$ Jonathan L. BAMBER, ${ }^{2}$ Martin J. SIEGERT, ${ }^{2}$ David G. VAUGHAN, ${ }^{3}$ \\ Hugh F. J. CORR ${ }^{3}$ \\ ${ }^{1}$ School of Geography, University of Leeds, Woodhouse Lane, Leeds LS2 9JT, UK \\ E-mail: d.m.rippin@leeds.ac.uk \\ ${ }^{2}$ Bristol Glaciology Centre, School of Geographical Sciences, University of Bristol, University Road, Bristol BS8 1SS, UK \\ ${ }^{3}$ British Antarctic Survey, Natural Environment Research Council, Madingley Road, Cambridge CB3 OET, UK
}

\begin{abstract}
Airborne radio-echo sounding investigations in the upper reaches of Bailey Ice Stream and Slessor Glacier, Coats Land, East Antarctica, have shown that enhanced-flow tributaries are associated with well-defined areas of relatively thicker ice, and are separated from each other by areas of relatively thinner ice. A numerical modelling study has revealed that while internal ice deformation might account for all the observed flow in inter-tributary areas and the majority in the Slessor tributaries, a significant proportion of the flow of Bailey tributary is attributable to basal motion. Further, investigations of depth-corrected basal reflection power indicate that the bed underlying both Bailey and Slessor enhanced-flow tributaries is significantly smoother than in the slower-moving inter-tributary areas. It is thus proposed that enhanced motion within Bailey tributary (and also perhaps Slessor) may be facilitated by a reduction in basal roughness, caused by the accumulation of water and/or sediments within subglacial valleys, or by the erosion and smoothing of bed obstacles.
\end{abstract}

\section{INTRODUCTION}

Ice sheets are traditionally considered to consist of slowmoving internal regions, which are drained by faster-moving outlet glaciers and ice streams, and these are considered to be separated from each other by abrupt onset regions and shear margins (Alley and Whillans, 1991). It is now, however, accepted, based on synthetic aperture radar interferometry (InSAR) and modelling of depth-averaged balance velocities, that this view is simplistic, and instead there is a network of enhanced-flow tributaries which penetrate into the interior of the ice sheet for several hundred kilometres (Joughin and others, 1999; Bamber and others, 2000). This complexity within ice-sheet interiors has significant implications for understanding ice-sheet flow and stability, and this is important for determining present-day and possible future changes in behaviour.

Most work to date on enhanced-flow tributaries has been carried out on the Siple Coast ice streams of West Antarctica. Here, most enhanced-flow tributaries follow valleys in subglacial topography (Joughin and others, 1999; Hulbe and others, 2000). This is because here the ice is thicker, and so driving stresses, and thus internal ice deformation, are greater. However, basal motion may also contribute to flow because the decrease in pressure-melting point (pmp) under thicker ice can lead to the production of subglacial water. In addition, deformable sediments may build up in subglacial valleys and, together with water, will facilitate basal motion (Anandakrishnan and others, 1998; Bell and others, 1998; Joughin and others, 1999). However, it is uncertain whether a similar mechanism might act in the East Antarctic ice sheet (EAIS), most of which is not grounded below sea level. Consequently, compared to the West Antarctic ice sheet (WAIS), marine sediments beneath the EAIS are unlikely to be as widespread (Alley and others,
1986; Blankenship and others, 1986; Joughin and others, 1999; Studinger and others, 2001).

In this paper, we investigate the significance of ice thickness for the flow regime of the enhanced-flow tributaries of Bailey Ice Stream and Slessor Glacier, and demonstrate that basal roughness is an important control on flow dynamics for these flow features.

\section{METHODOLOGY}

Airborne radio-echo sounding (RES) was carried out in the upper reaches of Bailey Ice Stream and Slessor Glacier, in Coats Land, East Antarctica, during the austral summer of $2001 / 02$. This region is characterized by an extensive network of enhanced-flow tributaries penetrating up to $\sim 600 \mathrm{~km}$ into the ice sheet, as well as significant intertributary areas (Bamber and other, 2000). A fuel depot and field camp were located at $78^{\circ} 58.60^{\prime} \mathrm{S}, 7^{\circ} 24.97^{\prime} \mathrm{W}$, from which a series of flights were carried out over an area measuring $200 \times 280 \mathrm{~km}^{2}$ (Fig. 1).

Approximately $5000 \mathrm{~km}$ of RES data were collected, at a centre frequency of $150 \mathrm{MHz}$, using the British Antarctic Survey (BAS) airborne radar system, mounted on a de Havilland DHC-6 Twin Otter aircraft. Lines were flown between predetermined waypoints, and locations were recorded using two Ashtech global positioning system (GPS) receivers. At an aircraft speed of $60 \mathrm{~m} \mathrm{~s}^{-1}$ the sampling interval was $25 \mathrm{~m}$, while the across-track spacing of the radar lines was $40 \mathrm{~km}$. The locations of the first return samples associated with the surface and bed were identified using a semi-automatic picking process in the seismic processing package ProMAX v2003.0. Positional data were determined using the Trimble package GPSurvey. The system and procedures are described in full elsewhere (Rippin and others, 2003). 


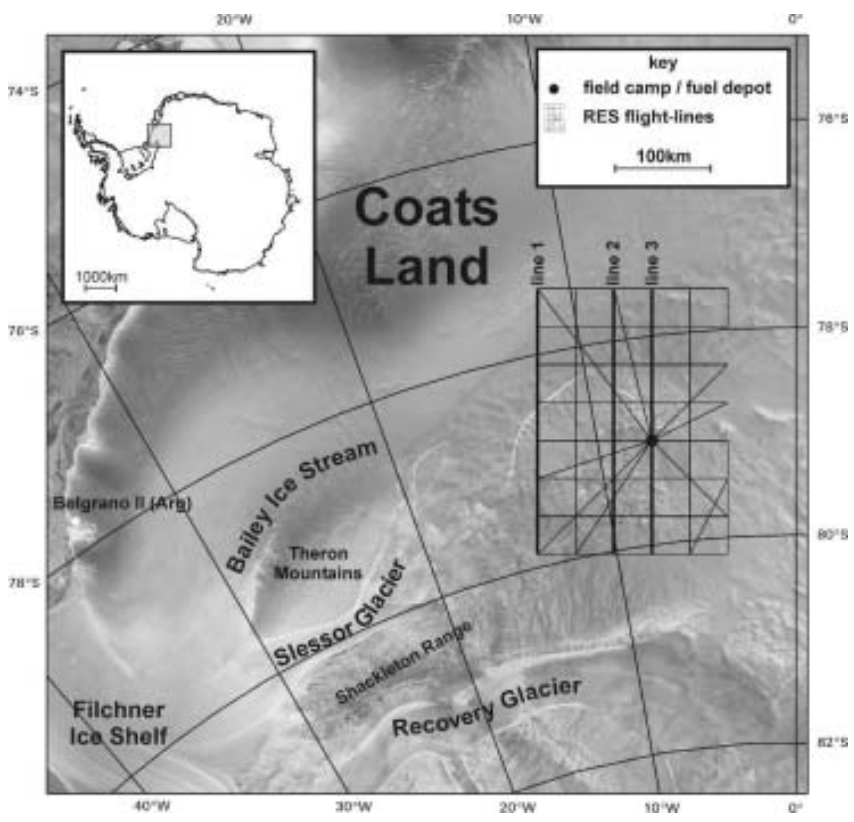

Fig. 1. Base map showing Bailey Ice Stream and Slessor Glacier, with flight-lines and the field camp/fuel depot marked. The three lines along which corrected basal reflection power $\left(\mathrm{BRP}_{\text {corr }}\right)$ is investigated are indicated, and marked with thicker black lines. Background is from the RADARSAT Antarctic Mapping Project (RAMP) mosaic of Antarctica (Jezek and RAMP Product Team, 2002). Location of base map is shown in the inset.

To investigate basal properties, power returns associated with the bed were determined. Previous studies have used RES power returns to differentiate between areas of frozen and unfrozen bed in Antarctica (Bentley and others, 1998; Gades and others, 2000), and to identify the location of subglacial lakes (e.g. Oswald and Robin, 1973; Siegert and Ridley, 1998). The power of a basal return is sensitive not only to the presence and distribution of water, but also to the thickness, porosity and distribution of a till layer, and also the roughness of the underlying bed (Berry, 1972, 1973; Gades, 1998). In West Antarctica, power returns have been analyzed and used to investigate basal conditions beneath ice streams and interstream areas. Beneath Siple Dome and Engelhardt Ice Ridge (former Ridge BC), ice has been identified which is frozen to the bed, while beneath Kamb Ice Stream (former Ice Stream C) and 'Siple Ice Stream' an unfrozen bed and the existence of either a basal layer of water or a till layer have been identified (Bentley and others, 1998; Gades and others, 2000)

Power returns associated with the bed were determined by identifying the maximum return amplitude in a window of 50 samples $(\sim 2 \mu \mathrm{s})$, immediately following the first return sample. Peak amplitudes were then converted to measurements of basal reflection power (BRP) based on known system parameters. In order to identify changes in BRP that are attributable to changes in basal conditions, the reduction of RES signal strength with path length (as a result of attenuation due to geometric spreading and absorption/reflection) must be accounted for (Bogorodsky and others, 1985). To empirically determine the relationship between ice thickness and BRP, an investigation was carried out in an inter-tributary area (between Bailey tributary and the northern limb of Slessor tributary), where balance velocities are uniformly low and bed conditions (i.e.
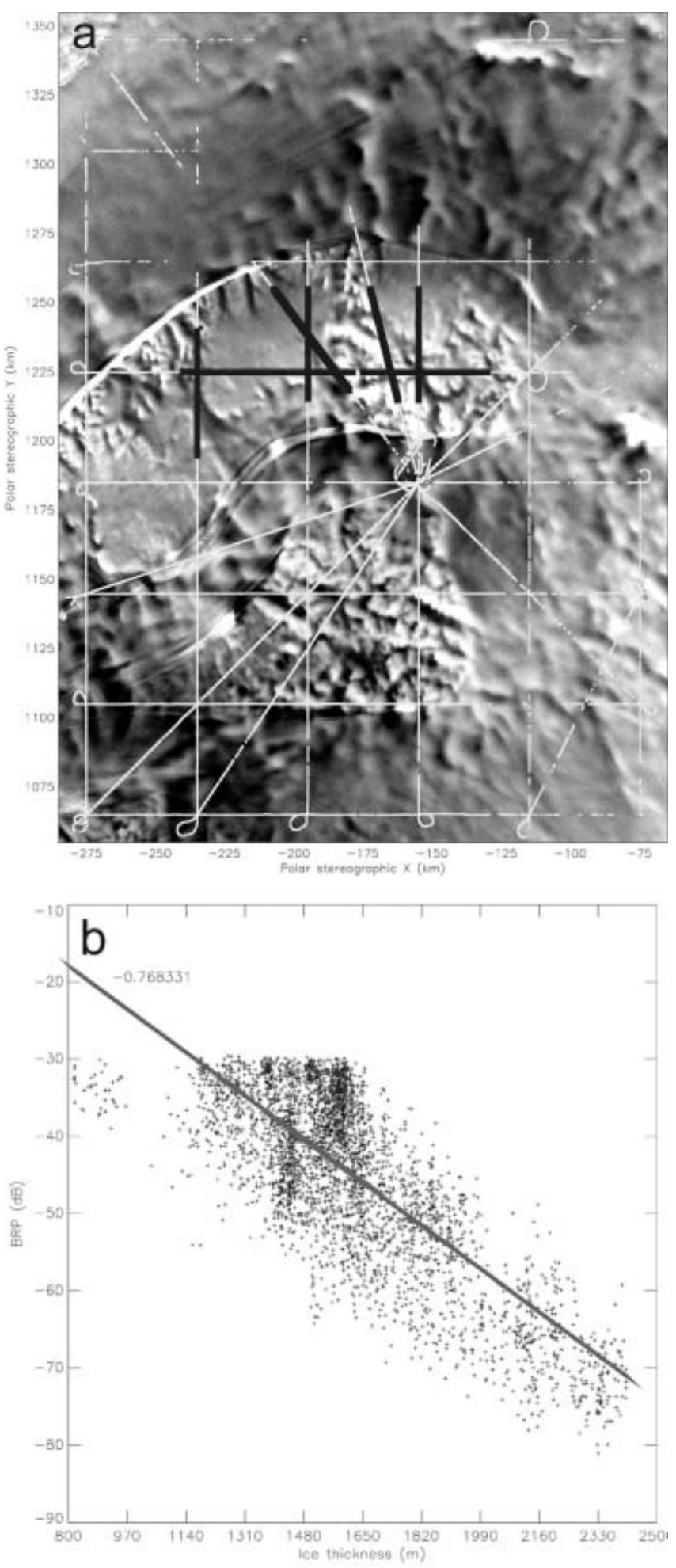

Fig. 2. (a) The location of points used to construct the relationship between ice thickness and BRP in the interstream area (black), as well as all RES flight-lines where bed returns were achieved (white). Background is part of the RAMP mosaic of Antarctica (Jezek and RAMP Product Team, 2002). (b) Relationship between ice thickness and BRP in the inter-tributary area, used for calculating theoretical BRP at any given ice thickness. Fitted linear regression and correlation coefficient displayed.

roughness and the presence of water and/or sediment) are believed to be uniform, yet where there is considerable variation in ice thickness $(\sim 815-2411 \mathrm{~m})$ (Fig. 2a). The relationship between ice thickness and measured BRP 


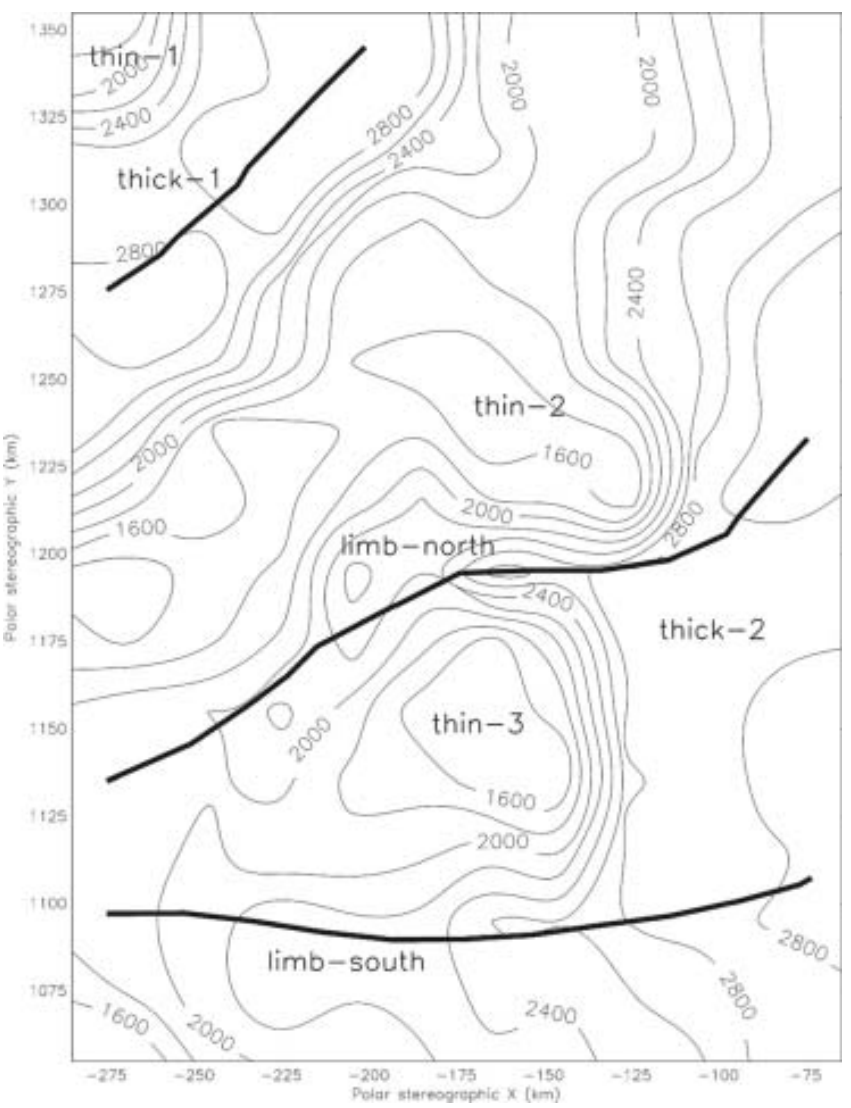

Fig. 3. Ice-thickness grid. Significant areas of thick and thin ice are marked as such. The flowlines associated with Bailey (top), Slessornorth (middle) and Slessor-south (bottom) are also shown by thick black lines. Gridcell resolution is $20 \mathrm{~km}$, and contours are in metres.

derived here was used to calculate a theoretical BRP at any given depth (Fig. 2b). This calculated BRP was then used to correct all data in the study area for variations in ice thickness, giving a corrected basal reflection power $\left(\mathrm{BRP}_{\mathrm{corr}}\right)$ which is the ratio of the measured BRP to the calculated BRP (Gades and others, 2000). Changes in $\mathrm{BRP}_{\text {corr }}$ across the study area are thus largely considered to be due to variations in basal properties, since the effects of ice thickness have been removed (Gades and others, 2000).

Values of $\mathrm{BRP}_{\text {corr }}$ were then compared with the location of enhanced-flow features and shear margins, as identified in the RADARSAT Antarctic Mapping Project (RAMP) mosaic of Antarctica (Jezek and RAMP Product Team, 2002), velocities derived from InSAR where available (personal communication from I. Joughin, 2002) and balance velocities. Balance velocities were calculated for the grounded part of the ice sheet from surface slope, ice thickness and mean net surface mass balance, using a two-dimensional finite-difference scheme (Budd and Warner, 1996; Bamber and others, 2000).

\section{RESULTS}

\section{Ice thickness}

Figure 3 shows a grid of interpolated ice thickness, at a $20 \times 20 \mathrm{~km}^{2}$ resolution. This grid is the difference between the surface and bed elevation grids, both of which were created from $>81000$ measurements using a kriging interpolation routine (Rippin and others, 2003).
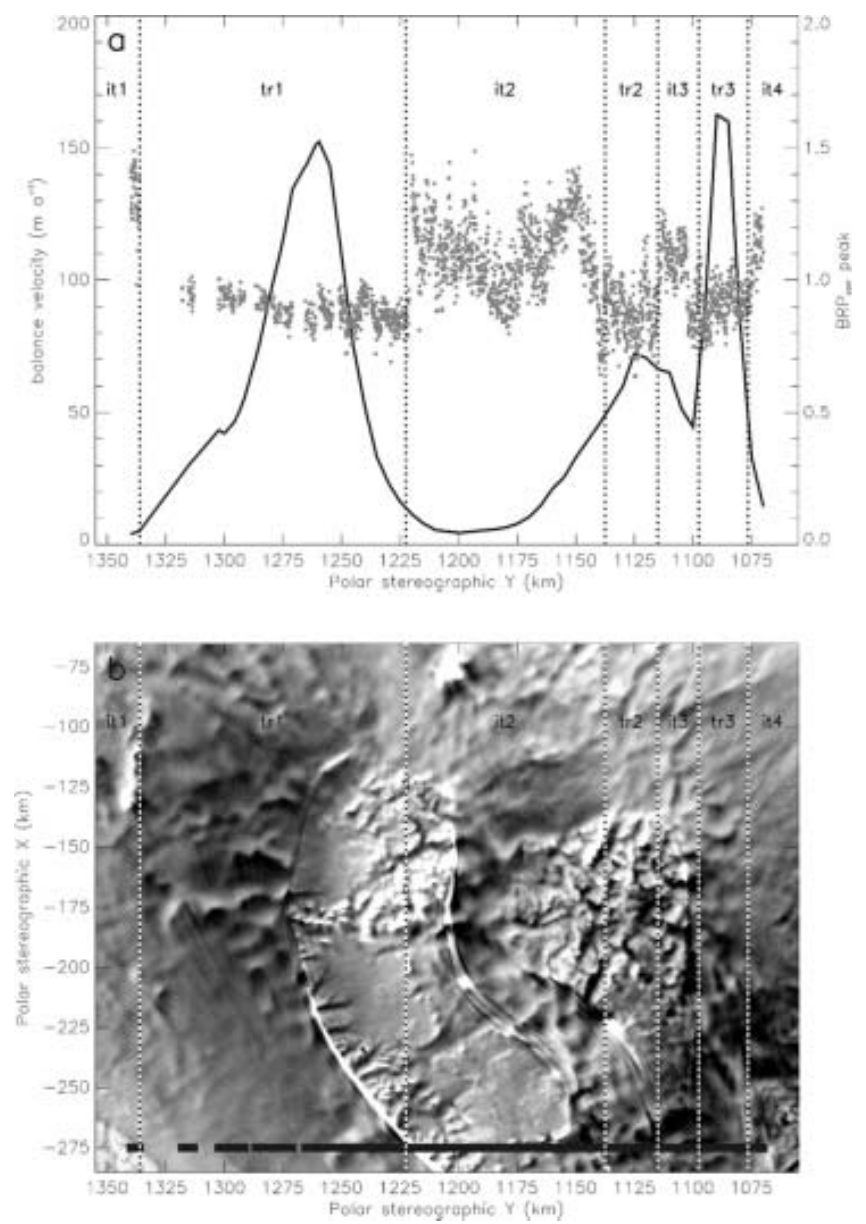

Fig. 4. (a) Corrected basal reflection power $\left(\mathrm{BRP}_{\mathrm{corr}}\right)$ (grey dots) and balance velocities (thick black line) along line 1. (b) Location of line 1 (horizontal black line), overlying RAMP mosaic (Jezek and RAMP Product Team, 2002). Dotted vertical lines in (a) and (b) divide each plot into tributary (tr) and inter-tributary (it) areas.

The ice-thickness map shows that there are two major areas of thick ice $(>2800 \mathrm{~m})$, named 'thick-1' and 'thick-2' (Fig. 3). Thick-1 is located to the northwest of the region, and thick-2 to the southeast (Fig. 3). Thick-2 also extends around an area of thin ice (named 'thin-3') in two distinct limbs (named 'limb-north' and 'limb-south'). Ice within these limbs is $\sim 2000-2400 \mathrm{~m}$ thick. In addition to thin-3 in the south, there are two other areas of thin ice (named 'thin- 1 ' and 'thin-2'). Most notably, thin-2 is a large elongate feature which separates thick-1 from limb-north. Finally, thin- 1 is located to the far northwest of the study area, adjacent to thick-1 (Fig. 3). Our new ice-thickness data are, on average, $\sim 164 \mathrm{~m}(\sim 4.2 \%$ of mean ice thickness) greater than in the BEDMAP database (Lythe and others, 2001), where existing coverage over the region was relatively sparse. In some regions, however, the discrepancy is much greater (Rippin and others, 2003).

\section{Basal reflection power}

Figures 4-6 show plots of $\mathrm{BRP}_{\text {corr }}$ along three transects across the study area, running approximately north-south. These figures show how $\mathrm{BRP}_{\text {corr }}$ varies within enhanced-flow tributaries and inter-tributary areas (based on the margins visible in the RAMP mosaic), and how balance velocities vary along these lines (cf. Fig. 1). Table 1 summarizes the $\mathrm{BRP}_{\text {corr }}$ and the standard deviation (SD) of $\mathrm{BRP}_{\text {corr }}$ in each 

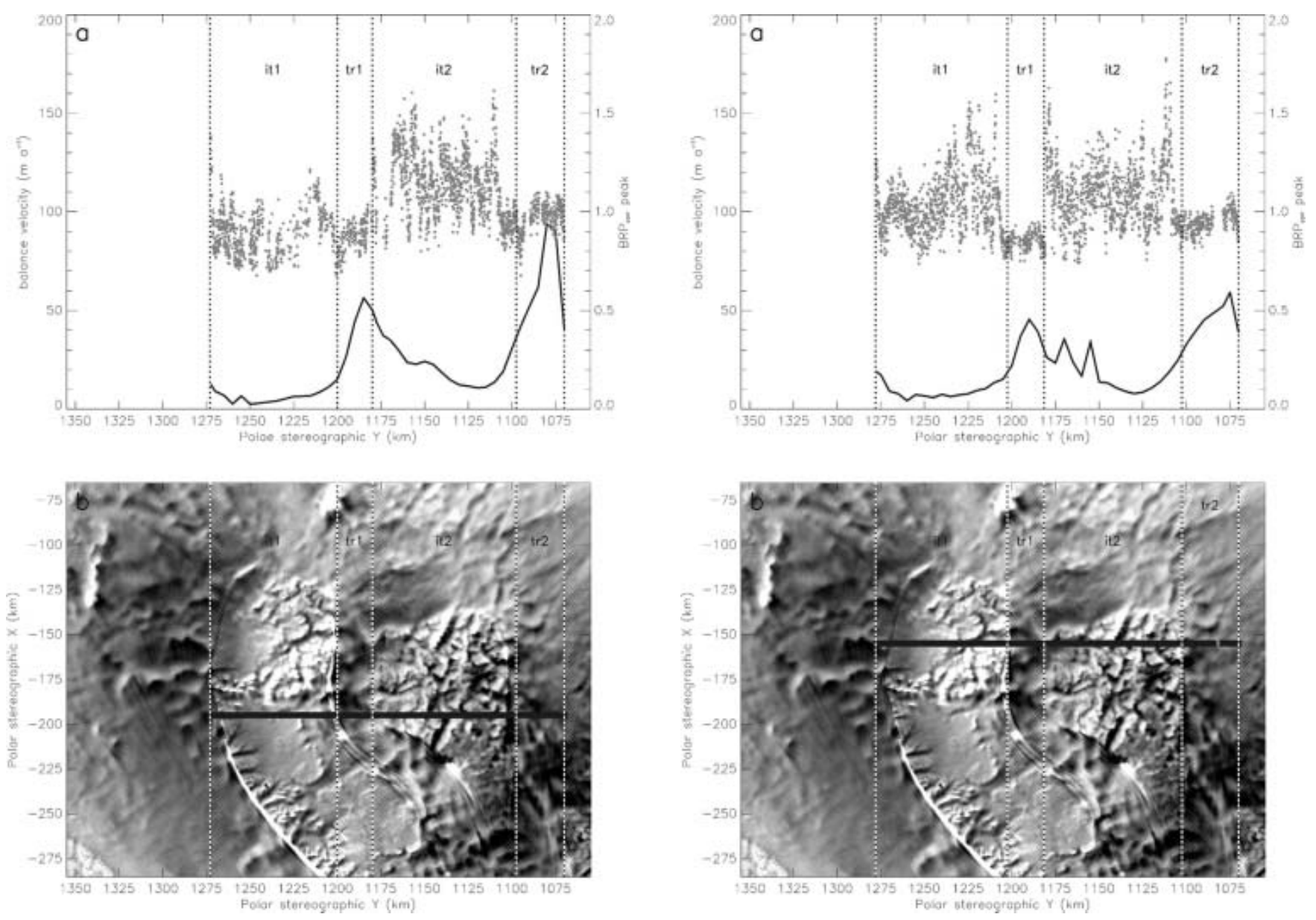

Fig. 5. Same as Figure 4, but along line 2 .

Fig. 6. Same as Figure 4, but along line 3.

tributary and inter-tributary area, as well as the mean balance velocities in each region.

Although the mean $\mathrm{BRP}_{\text {corr }}$ is similar in both intertributary and tributary regions, it is generally slightly higher in inter-tributary areas (Table 1). More clear, however, is the difference in standard deviation (SD) of $\mathrm{BRP}_{\text {corr, }}$ which is significantly greater in inter-tributary than in tributary areas. The mean SD in tributary areas is 0.065 , while the mean SD in inter-tributary areas is 0.133 , more than twice as much. Mean balance velocities are also three times higher in tributary areas $\left(63.48 \mathrm{~m} \mathrm{a}^{-1}\right)$ than in inter-tributary areas $\left(19.33 \mathrm{~m} \mathrm{a}^{-1}\right)$.

With respect to individual enhanced-flow tributaries, there are three measurements for Slessor-north (Table 1). All of these give very similar $\mathrm{BRP}_{\text {corr }}$ values, despite the decreasing balance velocity with distance up-tributary. There is only one measurement for Bailey Ice Stream, but this is also very similar to the Slessor-north values. The three Slessor-south values are all higher than those for Bailey Ice Stream and Slessor-north, although the measurement close to where the two Slessor tributaries join (line 1, tributary 3) is more similar to the Slessor-north values (Table 1).

\section{DISCUSSION}

Figure 7 shows InSAR and balance velocities overlying gridded ice thickness. InSAR data are not available for the whole area, and although balance velocities are qualita- tively similar, the precise location of tributaries, and velocity magnitudes differ slightly.

Both balance velocities and InSAR velocities indicate that Bailey Ice Stream tributary and the two Slessor Glacier tributaries are associated with thicker ice (thick-1, limbnorth and limb-south respectively), while areas of thinner ice occur in inter-tributary areas (Fig. 7; cf. Fig. 3). This clear correspondence between thicker ice and enhanced-flow tributaries is not surprising, since ice deformation is greater in thicker ice. However, since thicker ice also results in a lowering of the pmp at the bed, increased basal melting is possible, so enhanced basal motion may also be at least partly responsible for increased flow velocities.

In order to investigate the relative significance of ice deformation and basal motion, a simple model was employed in which longitudinal and shear stresses are ignored, and all flow is resisted by basal drag (Nye, 1952; Glen, 1955; Van der Veen, 1999). Under such conditions, the velocity which results from ice deformation within the ice column $(\mathrm{d} u)$ is expressed as:

$$
\mathrm{d} u=2 E A(\rho g \sin \alpha)^{n}(h-z)^{n} \mathrm{~d} z
$$

where $A$ is the flow-law parameter, $n$ is the flow-law exponent (3), $\rho$ is the mean density of ice $\left(917 \mathrm{~kg} \mathrm{~m}^{-3}\right), g$ is gravity $\left(9.81 \mathrm{~m} \mathrm{~s}^{-2}\right), \alpha$ is the surface slope, $z$ is the elevation of a point within the ice column (equal to 0 at the bed, and $h$ at the surface), $d z$ is the thickness of a layer of ice (Hutter, 1983; Paterson, 1994) and $E$ is an enhancement factor, equal to 8 in the tributaries (where accumulated strain results in 


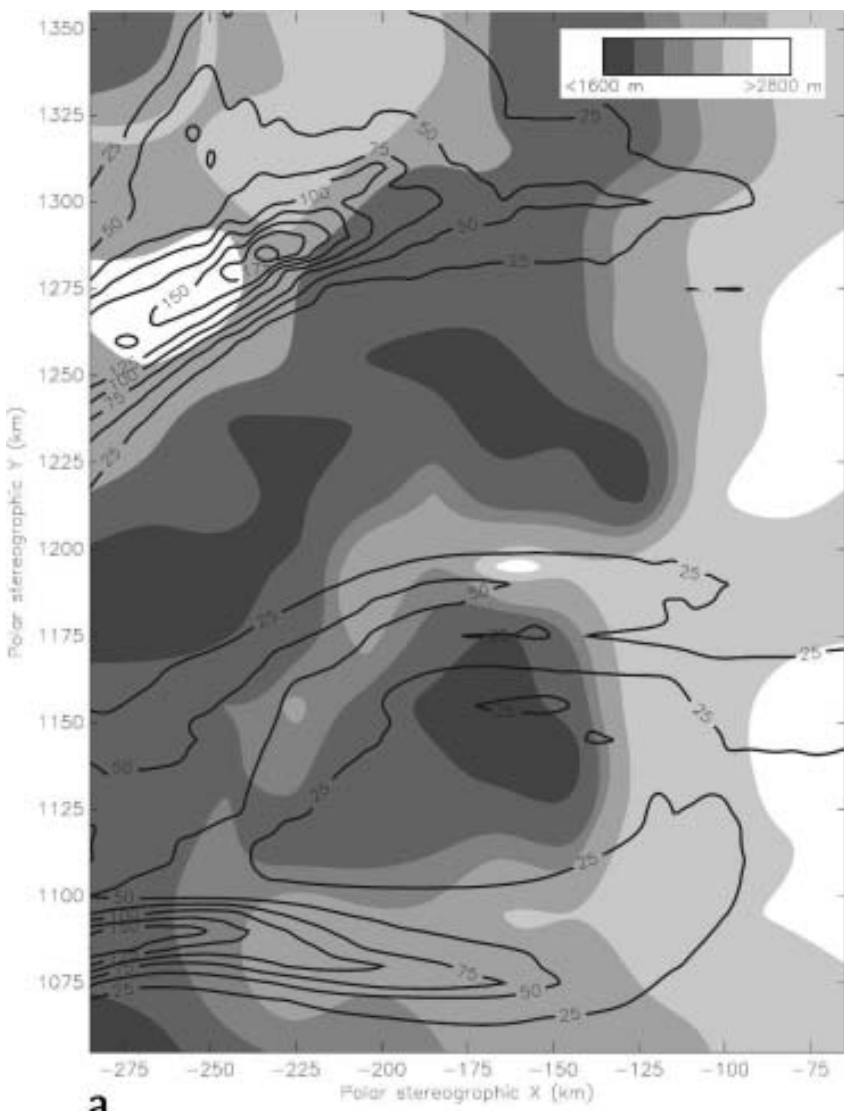

a

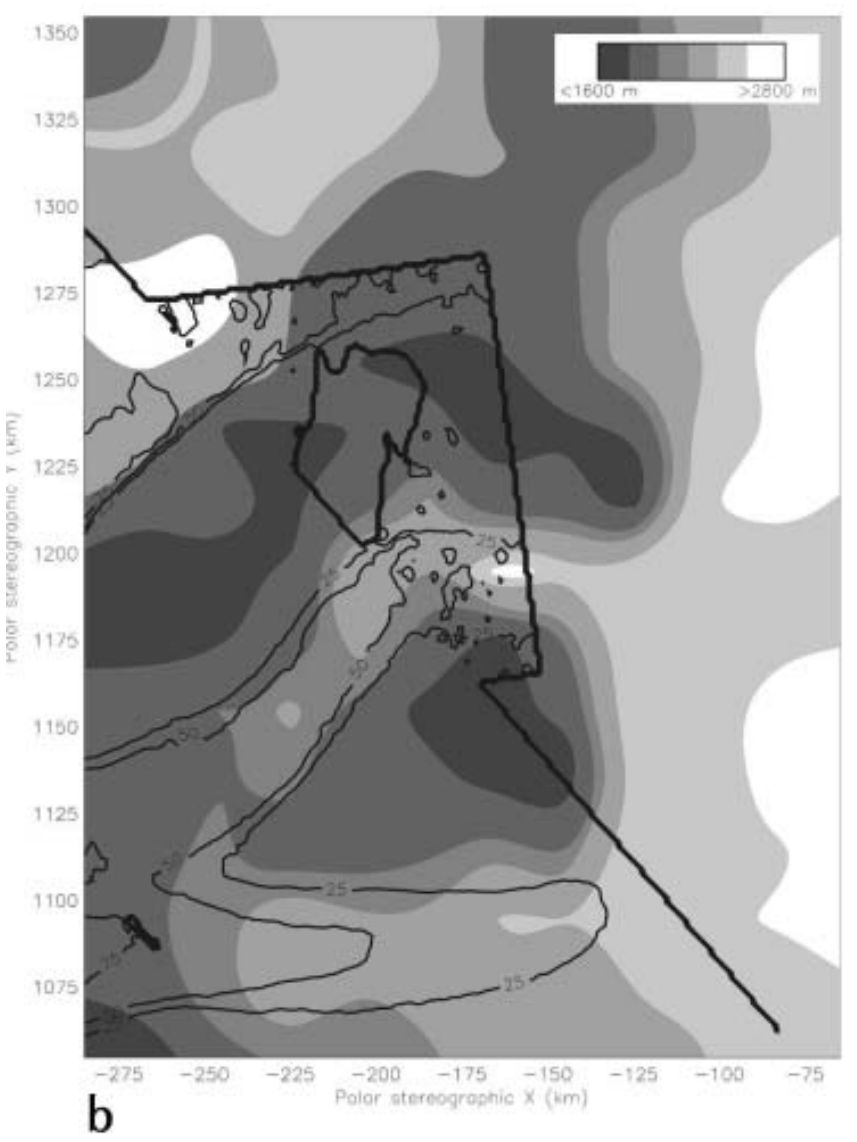

Fig. 7. (a) Balance velocities ( $\mathrm{m} \mathrm{a}^{-1}$ ) (black) contoured over gridded ice thickness (m) (grey-scale). (b) InSAR velocities $\left(\mathrm{m} \mathrm{a}^{-1}\right)$ (black) contoured over gridded ice thickness (m) (grey-scale).
Table 1. Mean and standard deviation (SD) of $\mathrm{BRP}_{\text {corr }}$ in a number of inter-tributary (it) and tributary (tr) regions along three transects (lines 1-3) running approximately north-south across the BaileySlessor onset region. Mean balance velocities (Balvel) within these regions are also shown $\left(\mathrm{ma}^{-1}\right)$. The suffix ${ }^{\mathrm{B}}$ in column 1 indicates that this tributary is part of Bailey Ice Stream, the suffix ${ }^{\mathrm{SN}}$ indicates it is part of Slessor-north, while ${ }^{\mathrm{SS}}$ indicates it is part of Slessor-south

\begin{tabular}{|c|c|c|c|c|c|c|}
\hline & $\begin{array}{c}\text { Mean } \\
\text { (it) }\end{array}$ & $\begin{array}{l}\text { SD } \\
\text { (it) }\end{array}$ & $\begin{array}{c}\text { Balvel } \\
\text { (it) }\end{array}$ & $\begin{array}{l}\text { Mean } \\
(\mathrm{tr})\end{array}$ & $\begin{array}{l}\text { SD } \\
(\operatorname{tr})\end{array}$ & $\begin{array}{c}\text { Balvel } \\
\text { (tr) }\end{array}$ \\
\hline line 1 it 1 & 1.329 & 0.098 & 4.40 & - & - & - \\
\hline line $1 \operatorname{tr} 1^{B}$ & - & - & - & 0.882 & 0.052 & 73.31 \\
\hline line 1 it2 & 1.092 & 0.144 & 15.02 & - & - & - \\
\hline line $1 \mathrm{tr} 2^{\mathrm{SN}}$ & - & - & - & 0.882 & 0.096 & 64.06 \\
\hline line 1 it 3 & 1.027 & 0.124 & 55.20 & - & - & - \\
\hline line $1 \mathrm{tr} 3^{\mathrm{SS}}$ & - & - & - & 0.909 & 0.071 & 120.24 \\
\hline line 1 it4 & 1.087 & 0.103 & 25.90 & - & - & - \\
\hline line 2 it1 & 0.896 & 0.117 & 6.14 & - & - & - \\
\hline line $2 \operatorname{tr} 1^{\mathrm{SN}}$ & - & - & - & 0.880 & 0.070 & 42.15 \\
\hline line 2 it2 & 1.138 & 0.162 & 20.76 & - & - & - \\
\hline line 2 tr2 ${ }^{s s}$ & - & - & - & 0.967 & 0.073 & 66.13 \\
\hline line 3 it1 & 1.041 & 0.153 & 9.12 & - & - & - \\
\hline line $3 \operatorname{tr} 1^{\mathrm{SN}}$ & - & - & - & 0.857 & 0.04 & 34.10 \\
\hline line 3 it2 & 1.090 & 0.162 & 18.10 & - & - & - \\
\hline line 3 tr2 ${ }^{s s}$ & - & - & - & 0.947 & 0.050 & 44.40 \\
\hline Mean & 1.088 & 0.133 & 19.33 & 0.903 & 0.065 & 63.48 \\
\hline
\end{tabular}

crystal alignment and fabric softening) and 1 in the intertributary area (Jacka and Budd, 1989; Van der Veen and Whillans, 1990). The total amount of deformation occurring is calculated by dividing the ice column into 100 equal thickness layers, and integrating throughout the depth.

The temperature profile throughout the ice column is unknown. This is of concern, however, since the flow-law parameter $A$ is taken to be a function of temperature and is the most significant unknown in the calculation (Paterson, 1994). A vertical temperature profile was thus constructed based on the work of Robin (1955; cf. Van der Veen, 1999). Takeda and others (2002), using large-scale modelling, have shown that large parts of the bed in this region are at the pmp. Under an ice thickness of $\sim 2290 \mathrm{~m}$, a pmp of $-1.33^{\circ} \mathrm{C}$ was calculated (Paterson, 1994). A surface temperature of $-35^{\circ} \mathrm{C}$ was also used (Giovinetto and others, 1990), and these limits were used to construct a temperature profile, which was in turn used to determine values of the flow-law parameter $A$.

Figure 8 shows the percentage of total motion which can be explained by ice deformation. Total motion was determined from InSAR velocities where they were available, and balance velocities (recalculated using the new ice-thickness data and calibrated to InSAR velocities where there is overlap) elsewhere (Rippin and others, 2003). In intertributary areas, the majority of flow is due to ice deformation. Similarly, most of the flow of the Slessor tributaries occurs by deformation, but basal motion must be invoked to explain $50-70 \%$ of flow in Bailey tributary (Fig. 8).

The investigations of $\mathrm{BRP}_{\text {corr }}$ indicate that there is a difference in basal conditions beneath the tributaries, as compared with the inter-tributary areas. Although values of $\mathrm{BRP}_{\text {corr }}$ are generally higher in inter-tributary areas, caution needs to be exercised in interpreting these results because of possible variations in englacial properties and spatial variations in attenuation (despite efforts to remove the effects of 
ice thickness). However, it is significant that all measurements of $\mathrm{BRP}_{\text {corr }}$ in Bailey and Slessor-north (as well as in Slessor-south, near the convergence with Slessor-north) are very similar, suggesting compatible basal conditions beneath these tributaries, which perhaps differ from conditions beneath much of Slessor-south (as well as, of course, intertributary areas). More interesting, however, and more conclusive, is the relative variability $(\mathrm{SD})$ of $\mathrm{BRP}_{\mathrm{corr}}$ which is unrelated to ice thickness and is twice as high in intertributary areas as in tributary areas (Figs 4-6; Table 1). This difference implies that, at the scale of the radio wavelength in ice $(\sim 1.12 \mathrm{~m})$, the bed in inter-tributary areas is rougher than in the tributaries. Such an observation supports the suggestion that there may be significant basal motion within the enhanced-flow tributaries (particularly Bailey), as compared with the inter-tributary areas, since a smoother bed within the tributaries implies fewer obstacles to sliding (perhaps as a result of erosion of obstacles and infilling of gaps between obstacles by sediment), and/or the presence of basal water.

\section{CONCLUSIONS}

A new map of ice thickness was produced for the Bailey/Slessor region of East Antarctica, from an airborne RES survey. This map indicates that the enhanced-flow tributaries of Bailey Ice Stream and Slessor Glacier are coincident with significantly thicker ice than the surrounding, slower-moving areas. A numerical modelling study indicates that virtually all flow within the slow-moving intertributary regions can be explained by ice deformation, as indeed can the majority of flow in the Slessor tributaries. However, a large proportion of the flow of Bailey enhancedflow tributary is dominated by basal motion. This conclusion is supported by less variable $\mathrm{BRP}_{\text {corr }}$ values within this tributary, which are interpreted as indicating a smoother bed. In contrast, the slower-moving inter-tributary areas are characterized by a much rougher bed. The Slessor tributaries are also characterized by a smoother bed, despite much of their flow being explained by ice deformation. It is possible that the relatively high enhancement factor used overestimates the significance of deformation here, and that some basal motion does occur. However, the use of a high enhancement factor puts a maximum bound on the amount of ice deformation occurring, and gives increased confidence that the residual basal motion in Bailey is real.

As in the Siple Coast ice streams of West Antarctica, enhanced-flow tributaries exist where ice is thicker, and are thus focused along subglacial topographic lows. Elevated velocities in the Bailey enhanced-flow tributary (and perhaps Slessor), however, are not purely a result of increased ice deformation, but are also due to increased basal motion. The precise mechanisms are difficult to determine, but it is likely that significant feedback mechanisms operate, whereby the pmp at the bed is reduced beneath thicker ice, and so there is an increased concentration of warmer ice, and thus liquid water, in these topographic lows. The resulting elevated sliding velocities will lead to increased erosion rates, which will accentuate the topographic troughs in which they lie and reduce bed roughness, and could provide the sediment required to create a deformable substrate (Bell and others, 1998). Since $\sim 36$ Myr BP, when the whole of East Antarctica was largely buried beneath ice (Ehrmann and Mackensen, 1992), a

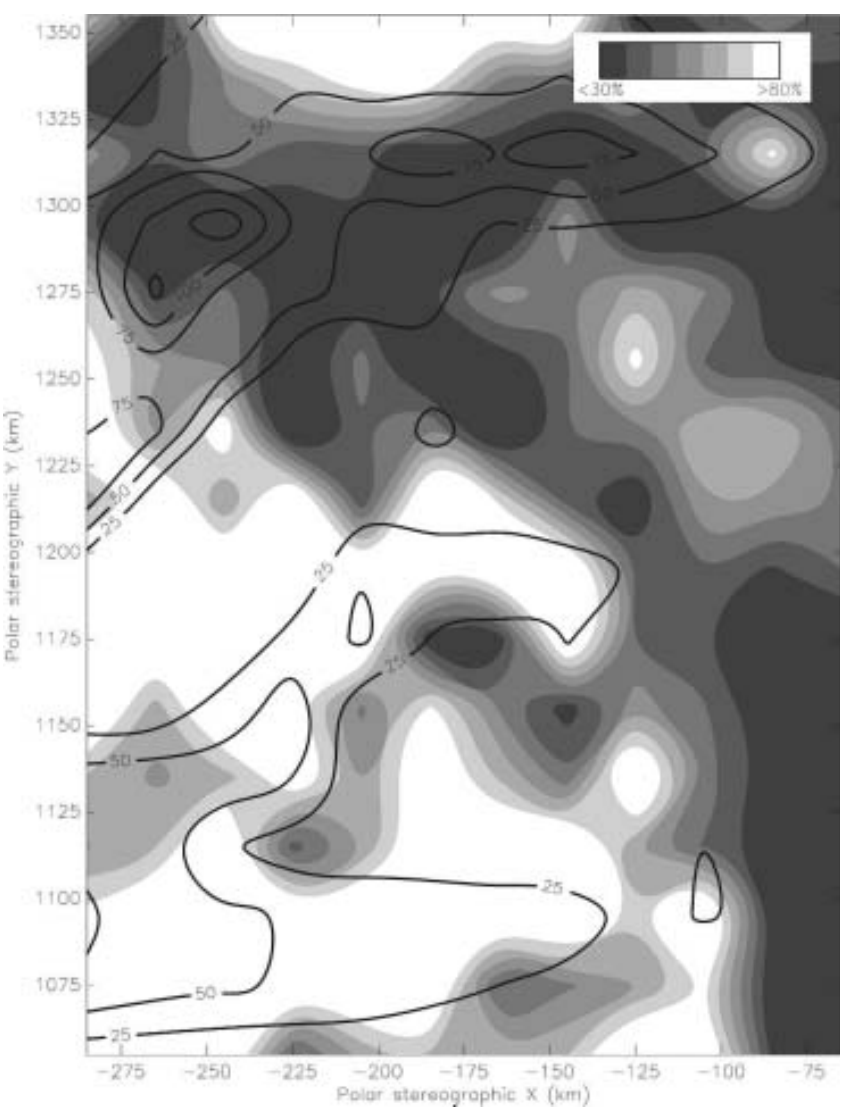

Fig. 8. Percentage of total velocity due to ice deformation (greyscale), with combined InSAR velocities and recalculated, calibrated balance velocities ( $\mathrm{m} \mathrm{a}^{-1}$ ) overlain (black contours).

significant subglacial layer could accumulate, sufficient to act as a lubricating basal till. The resultant enhanced velocities mean increased basal melting and more erosion, further increasing velocities.

\section{ACKNOWLEDGEMENTS}

This work was supported by UK Natural Environment Council grant GR3/AFI2/65. Antarctica fieldwork was made possible by the British Antarctic Survey (BAS) Administration and Logistics Division. Particular thanks are owed to D. Leatherdale, P. Jones and P. Woodroffe for assistance in the field. We are grateful to I. Joughin for providing InSAR velocity data, and to the editor, T. H. Jacka, and two referees, whose comments helped to improve this paper.

\section{REFERENCES}

Alley, R. B. and I. M. Whillans. 1991. Changes in the West Antarctic ice sheet. Science, 254(5034), 959-963.

Alley, R. B., D. D. Blankenship, C. R. Bentley and S. T. Rooney. 1986. Deformation of till beneath Ice Stream B, West Antarctica. Nature, 322(6074), 57-59.

Anandakrishnan, S., D. D. Blankenship, R. B. Alley and P. L. Stoffa. 1998. Influence of subglacial geology on the position of a West Antarctic ice stream from seismic observations. Nature, 394(6688), 62-65.

Bamber, J. L., D. G. Vaughan and I. Joughin. 2000. Widespread complex flow in the interior of the Antarctic ice sheet. Science, 287(5456), 1248-1250. 
Bell, R. E. and 6 others. 1998. Influence of subglacial geology on the onset of a West Antarctic ice stream from aerogeophysical observations. Nature, 394(6688), 58-62.

Bentley, C. R., N. Lord and C. Liu. 1998. Radar reflections reveal a wet bed beneath stagnant Ice Stream $\mathrm{C}$ and a frozen bed beneath ridge BC, West Antarctica. J. Glaciol., 44(146), 149-156.

Berry, M. V. 1972. Deducing form of surfaces from their diffracted echoes. J. Phys. A, 5(2), 272-291.

Berry, M. V. 1973. The statistical properties of echoes diffracted from rough surfaces. Philos. Trans. R. Soc. London, Ser. A, 273(1237), 611-658.

Blankenship, D. D., C.R. Bentley, S.T. Rooney and R. B. Alley. 1986. Seismic measurements reveal a saturated porous layer beneath an active Antarctic ice stream. Nature, 322(6074), 54-57.

Bogorodsky, V. V., C.R. Bentley and P.E. Gudmandsen. 1985. Radioglaciology. Dordrecht, etc., D. Reidel Publishing Co.

Budd, W. F. and R. C. Warner. 1996. A computer scheme for rapid calculations of balance-flux distributions. Ann. Glaciol., 23, 21-27.

Ehrmann, W. U. and A. Makensen. 1992. Sedimentological evidence for the formation of an East Antarctic ice sheet in Eocene/Oligocene time. Palaeogeogr., Palaeoclimatol., Palaeoecol., 93(1-2), 85-112.

Gades, A.M. 1998. Spatial and temporal variations of basal conditions beneath glaciers and ice sheets inferred from radio echo soundings. (Ph.D. thesis, University of Washington.)

Gades, A. M., C. F. Raymond, H. Conway and R. W. Jacobel. 2000. Bed properties of Siple Dome and adjacent ice streams, West Antarctica, inferred from radio-echo sounding measurements. J. Glaciol., 46(152), 88-94.

Giovinetto, M. B., N. M. Waters and C. R. Bentley. 1990. Dependence of Antarctic surface mass balance on temperature, elevation, and distance to open ocean. J. Geophys. Res., 95(D4), 3517-3531.

Glen, J.W. 1955. The creep of polycrystalline ice. Proc. R. Soc. London, Ser. A, 228(1175), 519-538.

Hulbe, C. L., I. R. Joughin, D. L. Morse and R.A. Bindschadler. 2000. Tributaries to West Antarctic ice streams: characteristics deduced from numerical modelling of ice flow. Ann. Glaciol., 31, 184-190.

Hutter, K. 1983. Theoretical glaciology; material science of ice and the mechanics of glaciers and ice sheets. Dordrecht, etc., D. Reidel Publishing Co.; Tokyo, Terra Scientific Publishing Co. Jacka, T. H. and W. F. Budd. 1989. Isotropic and anisotropic flow relations for ice dynamics. Ann. Glaciol., 12, 81-84.

Jezek, K. C. and RAMP Product Team. 2002. RAMP AMM-1 SAR image mosaic of Antarctica. Fairbanks, AK, Alaska SAR Facility, in association with the National Snow and Ice Data Center, Boulder, CO. (http://nsidc.org/data/docs/daac/nsidc0103_ramp _mosaic.gd.html.)

Joughin, I. and 7 others. 1999. Tributaries of West Antarctic ice streams revealed by RADARSAT interferometry. Science, 286(5438), 283-286.

Lythe, M. B., D. G. Vaughan and BEDMAP Consortium. 2001. BEDMAP: a new ice thickness and subglacial topographic model of Antarctica. J. Geophys. Res., 106(B6), 11,335-11,351.

Nye, J. F. 1952. The mechanics of glacier flow. J. Glaciol., 2(12), 82-93.

Oswald, G.K.A. and G. de Q. Robin. 1973. Lakes beneath the Antarctic ice sheet. Nature, 245(5423), 251-254.

Paterson, W.S.B. 1994. The physics of glaciers. Third edition. Oxford, etc., Elsevier.

Rippin, D.M., J.L. Bamber, M.J. Siegert, D.G. Vaughan and H. F. J. Corr. 2003. Basal topography and ice flow in the Bailey/ Slessor region of East Antarctica. J. Geophys. Res., 108(F1), 6008. (10.1029/2003JF000039.)

Robin, G. de Q. 1955. Ice movement and temperature distribution in glaciers and ice sheets. J. Glaciol., 2(18), 523-532.

Siegert, M. J. and J.K. Ridley. 1998. Determining basal ice-sheet conditions in the Dome $\mathrm{C}$ region of East Antarctica using satellite radar altimetry and airborne radio-echo sounding. J. Glaciol., 44(146), 1-8.

Studinger, M., R. E. Bell, D. D. Blankenship, C. A. Finn, R. A. Arko and D.L. Morse. 2001. Subglacial sediments: a regional geological template for ice flow in West Antarctica. Geophys. Res. Lett., 28(18), 3493-3496.

Takeda, A., S. Cox and A.J. Payne. 2002. Parallel numerical modelling of the Antarctic ice sheet. Computers Geosci., 28(6), 723-734.

Van der Veen, C.J. 1999. Fundamentals of glacier dynamics. Rotterdam, etc., A.A. Balkema Publishers.

Van der Veen, C. J. and I. M. Whillans. 1990. Flow laws for glacier ice: comparison of numerical predictions and field measurements. J. Glaciol., 36(124), 324-339. 